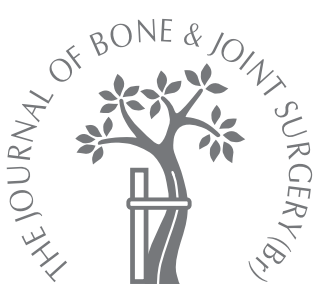

B. M. Wroblewski, P. D. Siney,

P. A. Fleming

From The John

Charnley Research

Institute,

Wrightington

Hospital, Wigan, England

\title{
The principle of low frictional torque in the Charnley total hip replacement
}

The design of the Charnley total hip replacement follows the principle of low frictional torque. It is based on the largest possible difference between the radius of the femoral head and that of the outer aspect of the acetabular component. The aim is to protect the bonecement interface by movement taking place at the smaller radius, the articulation. This is achieved in clinical practice by a $\mathbf{2 2 . 2 2 5} \mathbf{m m}$ diameter head articulating with a $\mathbf{4 0} \mathbf{~ m m}$ or $43 \mathrm{~mm}$ diameter acetabular component of ultra-high molecular weight polyethylene.

We compared the incidence of aseptic loosening of acetabular components with an outer diameter of $40 \mathrm{~mm}$ and $\mathbf{4 3} \mathrm{mm}$ at comparable depths of penetration with a mean follow-up of 17 years ( 1 to 40 ).

In cases with no measurable wear none of the acetabular components were loose. With increasing acetabular penetration there was an increased incidence of aseptic loosening which reflected the difference in the external radii, with $1.5 \%$ at $1 \mathrm{~mm}, 8.8 \%$ at $2 \mathrm{~mm}, 9.7 \%$ at $3 \mathrm{~mm}$ and $9.6 \%$ at $4 \mathrm{~mm}$ of penetration in favour of the larger $43 \mathrm{~mm}$ acetabular component.

Our findings support the Charnley principle of low frictional torque. The level of the benefit is in keeping with the predicted values.

In developing his total hip replacement (THR) Charnley used polytetrafluoroethylene (PTFE) first as 'synthetic cartilage' interposition shells ${ }^{1}$ then with a 'standard Moore prosthesis with a head 1-5/8 inches $(41.5 \mathrm{~mm})$ in diameter'. 2 Charnley was persuaded that 'resistance to the movement of the head in the socket is greatly reduced by reducing the radius of the ball and therefore reducing the 'moment' of the frictional force. If at the same time the radius of the exterior of the socket is made as large as possible, the moment of the frictional force between the socket and bone will be increased, and this will lessen the tendency for the socket to rotate against the bone'. "Since there was no way of estimating the rigours of service in the human hip joint over a period of years we had to proceed by trial and error ..... from the starting size of $41.5 \mathrm{~mm}$ the diameter was reduced to $28.5 \mathrm{~mm}$ then to $25 \mathrm{~mm}$ and finally to $22 \mathrm{~mm}{ }^{2}{ }^{2}$ It is that change from low friction, the property of the materials, to low frictional torque, the principle of the design, that marked the turning point in the evolution of the Charnley low frictional torque arthroplasty (LFA).

In an attempt to establish the optimum size of prosthetic metal heads in relation to the wear of plastic acetabular components,
Charnley, Kamangar and Longfield ${ }^{3}$ examined 100 explanted PTFE acetabular components and concluded that "...... the sphere should have a diameter not greater than half of the external convex diameter of the socket".

Andersson, Freeman and Swanson ${ }^{4}$ questioned the benefit of the low frictional torque in clinical practice. Using Charnley $22.225 \mathrm{~mm}$ diameter stainless steel heads with ultra-high molecular weight polyethylene (UHMWPE) and a McKee-Farrar metal-on-metal design cemented into cadaver pelves, the torsional moments needed to loosen the acetabular components were measured. They concluded that "the torsional moments were found to be from four to more than 20 times higher than the frictional moments measured". ${ }^{4}$ Their suggestion was that "late looseness of the acetabular component, was most likely due to thermal damage to the bone occurring at the time of polymerisation of the cement and the subsequent bone resorption". " No evidence was offered to support this statement. Fatigue fracture of bone, as a factor contributing to late loosening, was suggested to support the use of UHMWPE, although the "importance of this factor could not be estimated". ${ }^{4}$ Charnley ${ }^{5}$ argued that it was because of the low frictional torque that 
the radiographic demarcation of the bone-cement interface of the component did not progress to clinically symptomatic acetabular component loosening.

Ma, Kabo and Amstutz ${ }^{6}$ studied frictional torque both in resurfacing and in conventional hip replacement with cemented UHMWPE acetabular components, and concluded that frictional torque was proportional to the diameter of the head of the femoral component, becoming lower as the thickness of the UHMWPE acetabular component increased.

Ritter et $\mathrm{al}^{7}$ compared 67 Müller THRs with a $32 \mathrm{~mm}$ prosthetic head and an acetabular component of $50 \mathrm{~mm}$ diameter, with 300 Charnley arthroplasties with a $22 \mathrm{~mm}$ prosthetic head and acetabular component of $44 \mathrm{~mm}$ diameter, at a minimum follow-up of seven years. The acetabular component in the Müller series was found to be loose in $15 \%$, compared to $4 \%$ in the Charnley group ( $\mathrm{p}<0.032$ ). The survival at five and seven years was respectively $87 \%$ and $70 \%$ for the Müller and $94 \%$ and $86 \%$ for the Charnley $(\mathrm{p}<0.003)$. They concluded: "The difference is possibly due to the large Müller femoral head".?

Morrey and Ilstrup 8 assessed the correlation between the size of the head of the femoral component and acetabular revision in 6128 THRs and concluded: "although friction increases with the size of the femoral head, theoretically it remains significantly low so that the bone-cement interface is not at risk".

This conclusion must be questioned as friction does not increase with the size of the femoral head but frictional torque does. Furthermore, radiolucent lines were more frequent at the bone-cement interface of the acetabular component with the $32 \mathrm{~mm}$ diameter head: $29 \%$, as opposed to $15 \%$ with the $22 \mathrm{~mm}$ diameter head. 'Multivariate analysis showed that the $32 \mathrm{~mm}$ component was associated with a higher incidence of loosening than the $22 \mathrm{~mm}$ component'. The revision rate for aseptic loosening was also higher with the $32 \mathrm{~mm}, 6.8 \%$ as opposed to $2 \%$ to $3 \%$ for the $22 \mathrm{~mm}$ diameter head. The authors also found it "important to emphasise that the use of the $32 \mathrm{~mm}$ component was initiated approximately five years after considerable experience had been accumulated with the $22 \mathrm{~mm}$ component. This suggests that better results should have been achieved with the larger model: however, the opposite was true". ${ }^{8}$

In a study by Frankel et $\mathrm{al}^{9}{ }^{9}$ of the effect of the size of the femoral head on the radiographic demarcation of the acetabular bone-cement interface a comparison was made between $32 \mathrm{~mm}$ and $22 \mathrm{~mm}$ head sizes at 19 to 24 months' follow-up: "three-zone demarcation of the acetabular bone-cement interface was $56 \%$ of the $32 \mathrm{~mm}$ group as compared to $5 \%$ of the $22 \mathrm{~mm}$ group. When a sub-group of women under 60 years of age was examined to control variables, the high grade demarcation rates were $67 \%$ and $18 \%$ respectively". The conclusion was that "these results emphasize the adverse effects of large femoral head prostheses on bone-cement interface and underline the need for alternative methods of fixation".
The contribution of frictional torque to loosening of the bone-cement interface was examined in Tharies hip replacements. ${ }^{10}$ The authors concluded that frictional torque was not the primary factor in loosening of the prostheses with a large bearing surface, and that the higher friction and frictional torque can be tolerated if the generation of wear debris was sufficiently limited. ${ }^{10}$ The conclusions were based on 170 Tharies hip arthroplasties with a follow-up to 16 years. The overall revision rate was $47.1 \%$. The revision rate for aseptic loosening of the acetabular component was not dissimilar, irrespective of whether the components were small: $(23.5 \%)$, medium: $(23.5 \%)$ or large: $(26.5 \%)$. The number of hips in each group was just within the acceptable limits for survival analysis ${ }^{11}$ at the beginning but not at the end of the study. The authors also suggested that "polyethylene wear has a greater effect on the durability of fixation of the implant than does frictional torque". ${ }^{10}$ No evidence was offered to support this statement, and measurements of wear were not given.

We set out to investigate to what degree the theoretical advantages of the low frictional torque are reflected in the long-term results of the Charnley LFA, taking radiographic evidence of loosening of the acetabular component as the endpoint. ${ }^{12}$

Theoretical considerations. The diameter of the head of the Charnley stem is $22.225 \mathrm{~mm}$. The frictional torque is inversely proportional to the external radius of the UHMWPE component. With increasing depth of acetabular component penetration the radius of the worn part of the acetabular component will shorten, increasing the frictional torque. This will be reflected in the increasing incidence of aseptic loosening.

With the Charnley design the acetabular componenthead radius ratio is 1.8 for the $40 \mathrm{~mm}$ and 1.9 for the $43 \mathrm{~mm}$ diameter acetabular component. The difference, expressed as a percentage is $7 \%$ to $7.5 \%$. It was therefore postulated that the benefit of the larger, $43 \mathrm{~mm}$ diameter acetabular component should be reflected in a lower incidence of aseptic acetabular component loosening of $7 \%$ to $7.5 \%$ at comparable depths of penetration of the cup, irrespective of factors affecting wear.

\section{Materials and Methods}

Patients undergoing a Charnley LFA between November 1962 and December 1990 were included in an indefinite follow-up study. They were aged 50 years or less at the time of operation. ${ }^{13}$ Routine follow-up was at three months, then annually and subsequently according to the radiographic appearances, the level of patient activity, or the rate of wear of the acetabular component. ${ }^{13}$ The radiographic appearances of the bone-cement interface were classified according to Hodgkinson et al. ${ }^{12}$ Complete demarcation $>1 \mathrm{~mm}$ or migration of the acetabular component observed as a change in position on serial radiographs were taken to indicate loosening. Measurements of wear were made from 
Table I. Demographic details

\begin{tabular}{|c|c|c|c|}
\hline Acetabular component size (mm) & 40 & 43 & \\
\hline Number of hips & 453 & 879 & \\
\hline \multicolumn{4}{|l|}{ Gender } \\
\hline Male & 37 & 369 & \\
\hline Female & 301 & 309 & \\
\hline \multicolumn{4}{|l|}{ Age in yrs } \\
\hline Mean (range) & $40.3(15$ to 50$)$ & 41.7 & (19 to 50$)$ \\
\hline \multicolumn{4}{|l|}{ Weight in $\mathrm{kg}$} \\
\hline Mean (range) & $59 \quad$ (32 to 93$)$ & 69 & (30 to 108) \\
\hline Number of acetabular component loosening (\%) & $121(26.7)$ & 187 & $(21.3)$ \\
\hline
\end{tabular}

Table II. Acetabular component penetration and loosening

\begin{tabular}{|c|c|c|c|}
\hline \multicolumn{2}{|c|}{ Acetabular component } & \multirow[b]{2}{*}{ Number } & \multirow{2}{*}{$\begin{array}{l}\begin{array}{l}\text { Component } \\
\text { loosening }\end{array} \\
\text { Number (\%) }\end{array}$} \\
\hline Penetration $(\mathrm{mm})$ & $\begin{array}{l}\text { Size } \\
(\mathrm{mm})\end{array}$ & & \\
\hline \multirow[t]{2}{*}{0} & 40 & 8 & $0(0)$ \\
\hline & 43 & 21 & $0(0)$ \\
\hline \multirow{2}{*}{$\leq 1$} & 40 & 222 & $21(9.5)$ \\
\hline & 43 & 438 & $35(8.0)$ \\
\hline \multirow[t]{2}{*}{$\leq 2$} & 40 & 90 & $34(37.8)$ \\
\hline & 43 & 169 & $49(29.0)$ \\
\hline \multirow[t]{2}{*}{$\leq 3$} & 40 & 78 & $35(44.9)$ \\
\hline & 43 & 128 & $45(35.2)$ \\
\hline \multirow[t]{2}{*}{$\leq 4$} & 40 & 36 & $18(50.0)$ \\
\hline & 43 & 52 & $21(40.4)$ \\
\hline \multirow[t]{2}{*}{$>4$} & 40 & 19 & $13(68.4)$ \\
\hline & 43 & 71 & $37(52.1)$ \\
\hline
\end{tabular}

radiographs by an experienced Senior Research Fellow (PDS) by a method previously published, ${ }^{14}$ and recorded as penetration. We compared the incidence of aseptic loosening, at comparable depths of penetration, in patients who had received an acetabular component of $40 \mathrm{~mm}$ diameter with those in whom one of $43 \mathrm{~mm}$ diameter had been used.

\section{Results}

In the group of 1092 patients (1434 LFAs) there were 424 men and 668 women. Their mean age at surgery was 41 years (12 to 50$)$. At the latest review in September 2008, 98 patients $(9.0 \%)$ with 121 LFAs $(8.4 \%)$ did not have a continuing follow-up, 129 patients ( $11.8 \%$ ) with 181 LFAs $(12.6 \%)$ were known to have died, $263(24.1 \%)$ with 330 LFAs $(23.0 \%)$ had a revision, and 602 patients $(55.1 \%)$ with 802 LFAs $(55.9 \%)$ were attending follow-up and had not had a revision.

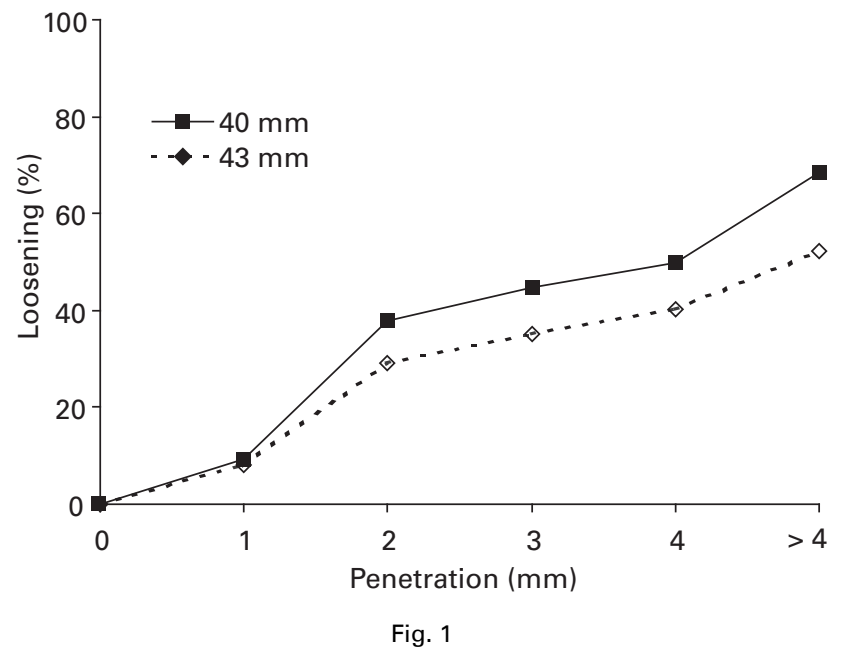

Graph showing penetration and loosening of the acetabular component.

The mean duration of follow-up for the whole group was 17 years ( 1 to 40 ), and for the patients still attending was 20 years and seven months (10 to 40 ).

We excluded 102 hips from the study. In 58 an offsetbore acetabular component ${ }^{15}$ had been used; this acetabular component has no chamfer and the eccentricity of the bore and the direction of penetration do not allow determination of the external radius of the acetabular component with respect to the head. In 16 others, the quality of the radiographs was unsuitable for the measurements. We also excluded 28 cases where deep infection was present. The remaining 1016 patients with 1332 LFAs were the subject of our study. The results are shown in Tables I and II and Figure 1. The direct correlation between the depth of acetabular penetration and the incidence of acetabular loosening confirms previous findings. ${ }^{13,16-20,21}$ The higher incidence of loosening of the $40 \mathrm{~mm}$ diameter component 
compared with the $43 \mathrm{~mm}$ diameter component, at comparable depths of penetration, supports the low frictional torque concept in the Charnley THR.

\section{Discussion}

The long-term benefit of low frictional torque, as reflected in the low incidence of aseptic loosening of the acetabular component, is the fundamental aspect of the design and practice of the Charnley hip replacement. In the original inventory, acetabular components of $43 \mathrm{~mm}$ and $40 \mathrm{~mm}$ diameter were available. The ratio of the radius of the acetabular component to the head was 1.9:1 and 1.8:1 respectively, close to the 2:1 suggested by Charnley et al. ${ }^{3}$ Provided this ratio remained, as in cases with no measurable wear, none of the acetabular components showed radiological evidence of loosening with a follow-up of up to 12 years. It is in this context that alumina ceramic and cross-linked polyethylene have proved beneficial. $^{22}$ With increasing depth of penetration of the acetabular component the increase in frictional torque is reflected in the progressive rise in the incidence of loosening. This was $1.5 \%$ at $1 \mathrm{~mm}, 8.8 \%$ at $2 \mathrm{~mm}, 9.7 \%$ at $3 \mathrm{~mm}$ and $9.6 \%$ at $4 \mathrm{~mm}$ of penetration in favour of the $43 \mathrm{~mm}$ diameter acetabular component. This is considered close to the predicted percentage difference in the frictional torques between the radii of the acetabular components of $40 \mathrm{~mm}$ and $43 \mathrm{~mm}$ diameter. With penetration of $>4 \mathrm{~mm}$, restriction of movement and impingement of the neck of the stem on the rim of the acetabular component will become the dominant factor leading to loosening. ${ }^{13,16-21}$ The available acetabular bone stock is the factor limiting the size of the acetabular component. Increasing the size of the acetabular component also increases its projected area and will reduce the pressure and the quality of cement injection. ${ }^{23}$ Cement pressurisation before insertion of the acetabular component is recommended. As the benefit of the $22.225 \mathrm{~mm}$ diameter head has been shown theoretically and supported by clinical results ${ }^{6-9}$ and in our long-term study in young patients, it is unclear to us why there is continuing trend to use larger-diameter heads. Increasing the diameter of the head can only be achieved at the expense of thickness of the acetabular component. Other than increasing frictional torque, it will require hard-on-hard articulation. With little or no room for cement, the need for alternative methods of fixation ${ }^{9}$ appears clear, though methods avoiding the use of cement have yet to offer comparable long-term results. The Charnley LFA has now been followed up for more than 40 years. Further improvements will come from a combination of low-wear materials ${ }^{22}$ while retaining the principle of low frictional torque.
This research was supported by the Peter Kershaw and John Charnley Charitable Trusts.

No benefits in any form have been received or will be received from a commercial party related directly or indirectly to the subject of this article.

\section{References}

1. Charnley J. Surgery of the hip-joint: present and future developments. Br Med J 1960;1:821-6.

2. Charnley J. Arthroplasty of the hip: a new operation. Lancet 1961;1:1129-32.

3. Charnley J, Kamangar A, Longfield MD. The optimum size of prosthetic heads in relation to the wear of plastic sockets in total replacement of the hip. Med Biol Eng 1969;7:31-9.

4. Andersson GB, Freeman MA, Swanson SA. Loosening of the cemented acetabular cup in total hip replacement. J Bone Joint Surg [Br] 1972;54-B:590-9.

5. Charnley J. Low friction arthroplasty of the hip: theory and practice. Berlin: SpringerVerlag, 1979

6. Ma SM, Kabo JM, Amstutz HC. Frictional torque in surface and conventional hip replacement. J Bone Joint Surg [Am] 1983;65-A:366-70.

7. Ritter MA, Stringer EA, Littrell DA, Williams JG. Correlation of prosthetic femoral head size and/or design with longevity of total hip arthroplasty. Clin Orthop 1983;176:252-7.

8. Morrey BF, Ilstrup D. Size of the femoral head and acetabular revision in total hipreplacement arthroplasty. J Bone Joint Surg [Am] 1989;71-A:50-5.

9. Frankel A, Balderston RA, Booth RE Jr, Rothman RH. Radiographic demarcation of the acetabular bone-cement interface: the effect of femoral head size. J Arthroplasty 1990;5(Suppl):1-3

10. Mai MT, Schmalzried TP, Dorey J, Campbell PA, Amstutz HC. The contribution of frictional torque to loosening at the cement-bone interface in Tharies hip replacements. J Bone Joint Surg [Am] 1996;78-A:505-11.

11. Lettin AW, Ware HS, Morris RW. Survivorship analysis and confidence intervals: an assessment with reference to the Stanmore total knee replacement. J Bone Joint Surg [Br] 1991;73-B:729-31.

12. Hodgkinson JP, Shelley P, Wroblewski BM. The correlation between the roentgenographic appearance and operative findings at the bone-cement junction of the socket in Charnley low friction arthroplasties. Clin Orthop 1988;228:105-9.

13. Wroblewski BM, Siney PD, Fleming PA. Charnley low-frictional torque arthroplasty in patients under the age of 51 years: follow-up to 33 years. J Bone Joint Surg [Br] 2002:84-B:540-3.

14. Griffith MJ, Seidenstein MK, Williams D, Charnley J. Socket wear in Charnley low friction arthroplasty of the hip. Clin Orthop 1978;137:37-47.

15. Izquierdo-Avino RJ, Siney PD, Wroblewski BM. Polyethylene wear in the Charnley offset bore acetabular cup: a radiological analysis. J Bone Joint Surg [Br] 1996;78-B:82-4.

16. Wroblewski BM. Charnley low friction arthroplasty in patients under the age of 40 years. In: Sevastik Y, Goldie I, eds. The young patient with degenerative hip disease. Stockholm: Almquist \& Wiksell, 1986:197-20.

17. Wroblewski BM, Siney PD. Charnley low-friction arthroplasty of the hip: long-term results. Clin Orthop 1993;292:191-201.

18. Wroblewski BM, Siney PD, Fleming PA. Wear of the cup in the Charnley LFA in the young patient. J Bone Joint Surg [Br] 2004;86-B:498-503.

19. Wroblewski BM, Siney PD, Fleming PA. Reduced diameter of the neck and its effect on the incidence of aseptic cup loosening in the Charnley LFA. J Bone Joint Surg [Br] 2005;87-B(Suppl 1):43

20. Wroblewski BM, Siney PD, Fleming PA. Effect of reduced diameter of the neck of the stem and its effect on the incidence of radiographic cup loosening and revisions in Charnley low-frictional torque arthroplasty. J Arthroplasty 2009;24:10-14.

21. Wroblewski BM. Direction and rate of socket wear in Charnley low-friction arthroplasty. J Bone Joint Surg [Br] 1985;67-B:757-61.

22. Wroblewski BM, Siney PD, Fleming PA. Low-friction arthroplasty of the hip using alumina ceramic and cross-linked polyethylene: a 17-year follow-up report. J Bone Joint Surg [Br] 2005;87-B:1220-1.

23. Wroblewski BM. Socket size and the expected quality of its fixation in the cemented total hip arthroplasty. Proc Inst Mech Eng [H] 1990;204:133-4. 